\title{
Birt-Hogg-Dubé syndrome presenting with spontaneous pneumothorax and extensive pulmonary cysts in the absence of skin lesions or renal pathology
}

\author{
Kartik Kumar, ${ }^{\ominus}$ Clare Ross
}

Department of Respiratory Medicine, St Mary's Hospital, Imperial College Healthcare NHS Trust, London, UK

\section{Correspondence to \\ Dr Kartik Kumar,}

kartik.kumar@nhs.net

Accepted 23 August 2019

Check for updates

(c) BMJ Publishing Group Limited 2019. No commercial re-use. See rights and permissions. Published by BMJ.

To cite: Kumar K, Ross C. BMJ Case Rep

2019:12:e231039.

doi:10.1136/bcr-2019-

231039

\section{SUMMARY}

Birt-Hogg-Dubé (BHD) syndrome is an autosomal dominant condition which classically manifests with skin lesions such as fibrofolliculomas, pulmonary cysts that predispose to spontaneous pneumothorax and an increased risk of developing renal cell carcinoma. We describe the case of a patient who presented with a spontaneous pneumothorax on a background of multiple lung cysts, in the absence of cutaneous fibrofolliculomas and renal tumours. A germline mutation in the folliculin FLCN gene was subsequently identified, confirming BHD syndrome. Our case highlights the importance of considering a broad differential diagnosis for the cause of a spontaneous pneumothorax in the presence of unexplained cystic lung disease and emphasises the value of maintaining a high index of clinical suspicion for inherited causes of pneumothoraces.

\section{BACKGROUND}

Birt-Hogg-Dubé (BHD) syndrome is an autosomal dominant condition which classically manifests with skin lesions, pulmonary cysts that predispose to spontaneous pneumothorax, and up to a $30 \%$ increased risk of developing renal cell carcinoma (RCC). ${ }^{1}$ It is caused by a germline mutation in the folliculin (FLCN) gene, which has a tumour suppressor function. ${ }^{2}$ Loss of folliculin function has been shown to result in enhanced cellular proliferation, which may contribute to oncogenesis. ${ }^{3}$

The manifestations of BHD syndrome may impose a significant clinical burden on patients. The pulmonary cysts seen in BHD are irregularly shaped, vary in size and are predominantly in the lower medial lung zones. ${ }^{4}$ The presence of these cysts predisposes patients to pneumothoraces. BHD accounts for up to $15 \%$ of cases of familial pneumothoraces and patients may have a 50-fold increased risk of developing a pneumothorax compared with the general population. ${ }^{56}$ The most common skin lesions are fibrofolliculomas, particularly on the head and neck, but may also include trichodiscomas and acrocordons. ${ }^{7}$ These lesions are typically benign. While the cutaneous manifestations and lung involvement in BHD do not require long-term follow-up per se, the significant risk of developing RCC mandates long-term renal surveillance. Renal tumours that may develop include hybrid oncocytic tumours, chromophobe RCCs and clear cell RCCs. ${ }^{8}$ Early recognition of BHD syndrome and subsequent regular interval imaging of the kidneys improves the likelihood of early RCC diagnosis and treatment should malignancy develop.

Here, we describe the case of a patient who presented with a spontaneous pneumothorax on a background of multiple lung cysts, in the absence of cutaneous fibrofolliculomas and renal tumours. Subsequent genetic testing confirmed a mutation in the FLCN gene.

\section{CASE PRESENTATION}

A Moroccan man in his 50s was admitted to hospital with acute dyspnoea and left-sided pleuritic chest pain. Other than a previous history of very briefly smoking cigarettes, he had no previous medical history. Initial blood test results were unremarkable. An ECG showed incidental left bundle branch block and an echocardiogram was normal. Chest X-ray revealed a large left pneumothorax, which was treated with an intercostal chest drain. High-resolution CT imaging (figure 1) demonstrated: the left pneumothorax; multiple cysts throughout both lungs, some of which were located subpleurally; and a $4.8 \mathrm{~cm}$ cyst in the right kidney.

\section{DIFFERENTIAL DIAGNOSIS}

Based on the radiographic appearances (figure 1), differential diagnoses included BHD syndrome, lymphangioleiomyomatosis, Langerhans cell histiocytosis and lymphocytic interstitial pneumonia. However, he did not initially appear to have the classic phenotype of any of these conditions.

\section{TREATMENT}

After 9 days, following reinflation of the lung and cessation of the air leak, the chest drain was removed. A subsequent chest X-ray revealed recurrence of the left pneumothorax, necessitating reinsertion of an intercostal chest drain. The left lung failed to reinflate despite maintaining the chest drain on low vac wall suction for seven further days. The patient underwent video-assisted thoracoscopic apicectomy, multiple bullectomies, parietal pleurectomy and diaphragmatic basal mechanical abrasion. Histology revealed multiple bullae and blebs but no evidence of atypia or malignancy. He recovered well and was discharged from hospital. 


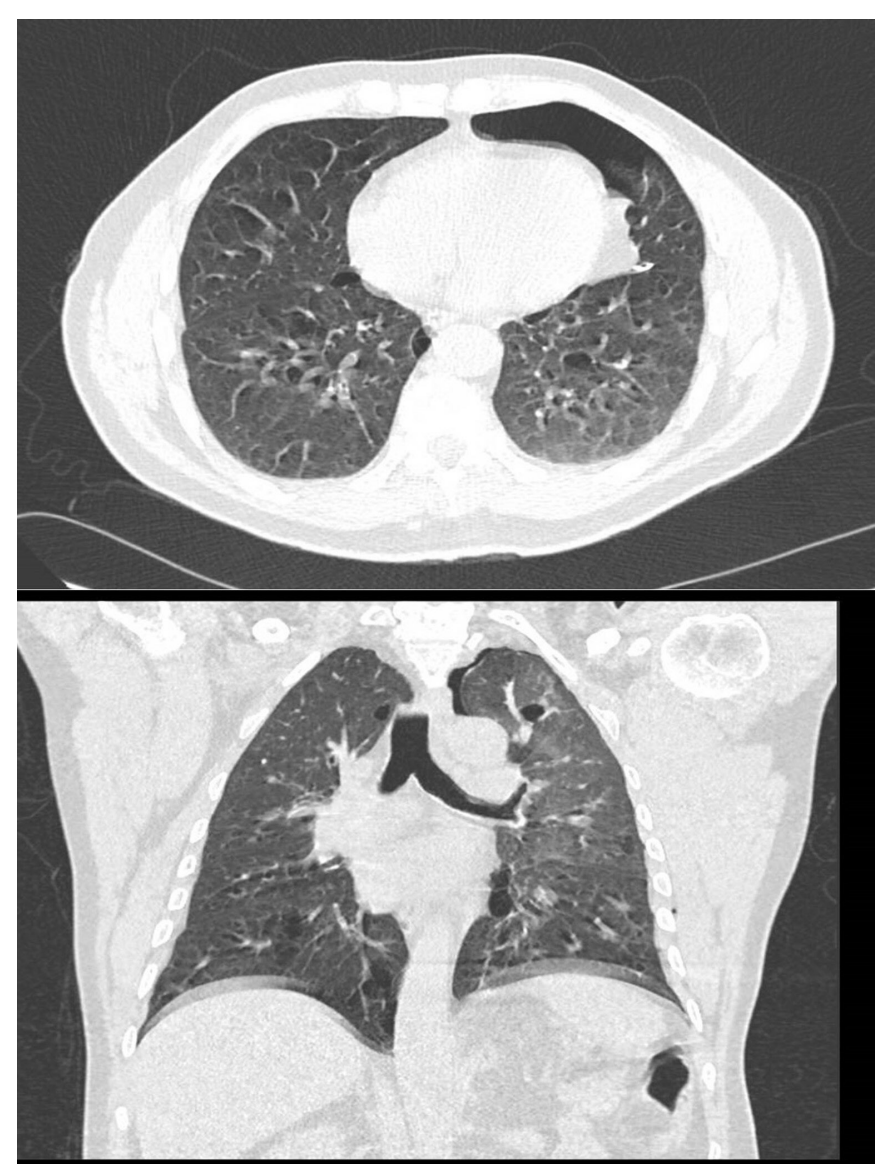

Figure 1 Axial (top) and coronal (bottom) views of HR CT chest scan demonstrating a left pneumothorax and widespread pulmonary cysts.

\section{OUTCOME AND FOLLOW-UP}

The patient was reviewed in the pleural disease clinic following discharge from hospital. There was no personal history of skin lesions, malignancy or breathlessness on exertion. There was no known family history of pneumothoraces, renal cancer or facial papules. Tests for antinuclear antibody and HIV infection were negative. An ultrasound scan of the kidneys confirmed the presence of an avascular cortical cyst in the right kidney measuring $48 \times 50 \times 48 \mathrm{~mm}$. Subsequent blood sent for genetic analysis identified the heterozygous variant c. $1176+1 \mathrm{dupG}$ at a splice donor site of the folliculin FLCN gene, thus confirming BHD syndrome.

Arrangements were made for renal surveillance imaging, longterm pleural disease clinic outpatient follow-up and genetic counselling of first-degree relatives (the outcome of which is currently unknown). Eighteen months following his initial presentation to hospital, the patient remains well with no pneumothorax recurrence.

\section{DISCUSSION}

The prevalence of pneumothoraces among BHD patients ranges between $24 \%$ and $38 \% .{ }^{9}$ FLCN mutations resulting in a primary spontaneous pneumothorax in the absence of skin lesions and renal pathology have previously been reported in the literature. In an American study of 12 families where there were at least two first-degree relatives who had experienced a spontaneous pneumothorax, members of two families demonstrated mutations in the FLCN gene; but none of the affected family members exhibited cutaneous manifestations of BHD syndrome or renal tumours. ${ }^{10}$ A Finnish study of a large family in which several members had experienced one or more primary spontaneous pneumothoraces demonstrated a deletion mutation in the FLCN gene in all affected family members; no skin or renal involvement was identified in any cases. ${ }^{11}$ Additionally, a Chinese study has identified multiple novel mutations in the FLCN gene among patients with both sporadic and familial isolated primary spontaneous pneumothoraces. ${ }^{12}$ While clinical scoring systems have been developed to attempt to predict which patients presenting with primary spontaneous pneumothoraces may have BHD syndrome, these currently require clinical validation and further study. ${ }^{13}$

Although the pulmonary cysts in our patient were located throughout both lungs, pulmonary cysts in BHD syndrome typically exhibit a basal distribution, with cysts frequently seen in the lower medial and subpleural regions of the lung. ${ }^{414} 15$ Identifying the radiological distribution and characteristics of pulmonary cysts can help to differentiate between the various causes of cystic lung disease. Cysts in lymphangioleiomyomatosis are regular and distributed diffusely; cysts in Langerhans cell histiocytosis are irregular and tend to be in the upper zones; and cysts in lymphocytic interstitial pneumonia are diffusely distributed in the lower lobes. ${ }^{15}$

Long-term renal surveillance in BHD patients is essential to detect renal malignancies that may arise. Although our patient initially underwent an ultrasound scan of the renal tract to screen for renal pathology, it has been suggested that ultrasonography may miss small or isoechoic lesions associated with BHD syndrome and that abdominal CT or MRI using intravenous contrast would be the preferred imaging modalities to detect BHD-associated renal lesions. ${ }^{16}{ }^{17}$ As renal cancer in BHD syndrome usually occurs between the ages of 25 and 75 years, surveillance from the age of 20 years has been advocated. ${ }^{18}$ There is no consensus on the frequency of renal imaging: it has been suggested that interval scans should take place every 2 years if no tumours are seen, but more frequently if small tumours are identified. ${ }^{5}$

\section{Learning points}

Birt-Hogg-Dubé (BHD) syndrome may initially present exclusively with pulmonary involvement and without the classical dermatological or renal pathology that is typically seen in the condition.

- The presence of widespread pulmonary cysts of unclear aetiology, or the occurrence of a spontaneous pneumothorax in the context of cystic lung disease, should prompt genetic testing for an underlying inherited cause.

- The distribution and characteristics of pulmonary cysts may provide a clue as to their underlying aetiology; cysts in BHD syndrome are typically basally distributed and they are frequently seen in the lower medial and subpleural regions of the lung.

- Long-term renal surveillance of BHD patients should be undertaken by abdominal CT or MRI using intravenous contrast, as ultrasonography may miss small or isoechoic renal lesions; there is currently no consensus on the time interval between scans.

- The potential risk of BHD syndrome in relatives of affected individuals should be assessed in the clinical history and genetic testing should be offered to first-degree relatives. 
Our patient did not have any family history suggestive of BHD syndrome. It is important to assess the potential risk of BHD syndrome affecting first-degree relatives of BHD patients. Given the phenotypic variability of the condition among affected family members, it should be remembered that relatives may present with just one or any combination of the pulmonary, cutaneous or renal manifestations of the disease. ${ }^{19}$

Our patient did not have the classical skin lesions associated with BHD and had only a single, simple renal cyst. This case therefore highlights the importance of considering a broad differential diagnosis for the cause of a spontaneous pneumothorax in the presence of unexplained cystic lung disease and emphasises the value of maintaining a high index of clinical suspicion for inherited causes of pneumothoraces.

Contributors $\mathrm{KK}$ and $\mathrm{CR}$ were both directly involved in the clinical care of the described case. KK and CR both planned the format of the article. KK drafted the initial manuscript. CR critically revised the manuscript for content. KK and CR both approved the version of the manuscript that was submitted for publication.

Funding The authors have not declared a specific grant for this research from any funding agency in the public, commercial or not-for-profit sectors.

Competing interests None declared.

Patient consent for publication Obtained.

Provenance and peer review Not commissioned; externally peer reviewed.

\section{REFERENCES}

1 Jensen DK, Villumsen A, Skytte A-B, et al. Birt-Hogg-Dubé syndrome: a case report and a review of the literature. Eur Clin Respir J 2017;4:1292378.

2 Nickerson ML, Warren MB, Toro JR, et al. Mutations in a novel gene lead to kidney tumors, lung wall defects, and benign tumors of the hair follicle in patients with the Birt-Hogg-Dubé syndrome. Cancer Cell 2002;2:157-64.

3 Hasumi H, Hasumi Y, Baba M, et al. H255Y and K508R missense mutations in tumour suppressor folliculin (FLCN) promote kidney cell proliferation. Hum Mol Genet 2017;26:354-66.
4 Tobino K, Gunji Y, Kurihara M, et al. Characteristics of pulmonary cysts in Birt-HoggDubé syndrome: thin-section CT findings of the chest in 12 patients. Eur J Radiol 2011;77:403-9.

5 Scott RM, Henske EP, Raby B, et al. Familial pneumothorax: towards precision medicine. Thorax 2018;73:270-6.

6 Zbar B, Alvord WG, Glenn G, et al. Risk of renal and colonic neoplasms and spontaneous pneumothorax in the Birt-Hogg-Dubé syndrome. Cancer Epidemiol Biomarkers Prev 2002;11:393-400.

7 Schmidt LS, Linehan WM. Molecular genetics and clinical features of Birt-Hogg-Dubé syndrome. Nat Rev Urol 2015;12:558-69.

8 Pavlovich CP, Walther MM, Eyler RA, et al. Renal Tumors in the Birt-Hogg-Dubé Syndrome. Am I Surg Pathol 2002;26:1542-52.

9 Houweling AC, Gijezen LM, Jonker MA, et al. Renal cancer and pneumothorax risk in Birt-Hogg-Dubé syndrome; an analysis of 115 FLCN mutation carriers from 35 BHD families. Br J Cancer 2011;105:1912-9.

10 Graham RB, Nolasco M, Peterlin B, et al. Nonsense mutations in folliculin presenting as isolated familial spontaneous pneumothorax in adults. Am J Respir Crit Care Med 2005; 172:39-44

11 Painter JN, Tapanainen H, Somer M, et al. A 4-bp Deletion in the Birt-Hogg-Dubé Gene (FLCN) causes dominantly inherited spontaneous pneumothorax. Am J Hum Genet 2005;76:522-7.

12 Ren H-Z, Zhu C-C, Yang C, et al. Mutation analysis of the FLCN gene in Chinese patients with sporadic and familial isolated primary spontaneous pneumothorax. Clin Genet 2008:74:178-83.

13 Ebana H, Mizobuchi T, Kurihara M, et al. Novel clinical scoring system to identify patients with pneumothorax with suspicion for Birt-Hogg-Dubé syndrome. Respirology 2018;23:414-8.

14 Furuya $\mathrm{M}$, Nakatani Y. Birt-Hogg-Dubé syndrome: clinicopathological features of the lung. J Clin Pathol 2013;66:178-86.

15 Baldi BG, Carvalho CRR, Dias OM, et al. Diffuse cystic lung diseases: differential diagnosis. J Bras Pneumol 2017;43:140-9.

16 Stamatakis L, Metwalli AR, Middelton LA, et al. Diagnosis and management of BHDassociated kidney cancer. Fam Cancer 2013;12:397-402.

17 Choyke PL, Glenn GM, Walther MM, et al. Hereditary renal cancers. Radiology 2003;226:33-46.

18 Menko FH, van Steensel MAM, Giraud S, et al. Birt-Hogg-Dubé syndrome: diagnosis and management. Lancet Oncol 2009;10:1199-206.

19 Schmidt LS, Warren MB, Nickerson ML, et al. Birt-Hogg-Dubé syndrome, a genodermatosis associated with spontaneous pneumothorax and kidney neoplasia, maps to chromosome 17p11.2. Am J Hum Genet 2001;69:876-82.

Copyright 2019 BMJ Publishing Group. All rights reserved. For permission to reuse any of this content visit

https://www.bmj.com/company/products-services/rights-and-licensing/permissions/

BMJ Case Report Fellows may re-use this article for personal use and teaching without any further permission.

Become a Fellow of BMJ Case Reports today and you can:

- Submit as many cases as you like

- Enjoy fast sympathetic peer review and rapid publication of accepted articles

Access all the published articles

- Re-use any of the published material for personal use and teaching without further permission

Customer Service

If you have any further queries about your subscription, please contact our customer services team on +44 (0) 2071111105 or via email at support@bmj.com.

Visit casereports.bmj.com for more articles like this and to become a Fellow 